Provided for non-commercial research and education use. Not for reproduction, distribution or commercial use.

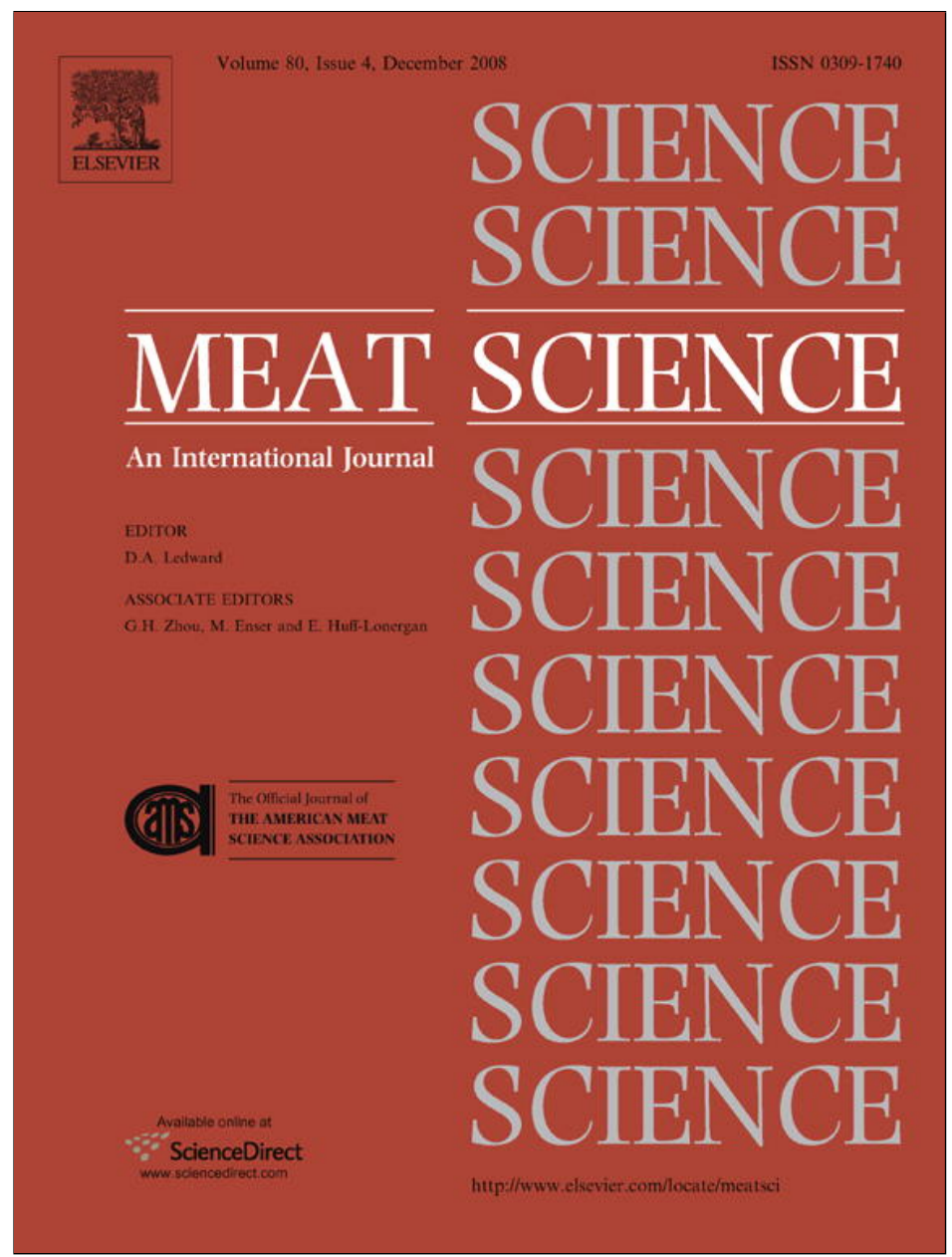

This article appeared in a journal published by Elsevier. The attached copy is furnished to the author for internal non-commercial research and education use, including for instruction at the authors institution and sharing with colleagues.

Other uses, including reproduction and distribution, or selling or licensing copies, or posting to personal, institutional or third party websites are prohibited.

In most cases authors are permitted to post their version of the article (e.g. in Word or Tex form) to their personal website or institutional repository. Authors requiring further information regarding Elsevier's archiving and manuscript policies are encouraged to visit:

http://www.elsevier.com/copyright 


\title{
Effect of feeding fermentable fibre-rich feedstuffs on meat quality with emphasis on chemical and sensory boar taint in entire male and female pigs
}

\author{
Laurits Lydehøj Hansen $^{\mathrm{a}, *}$, Sandra Stolzenbach ${ }^{\mathrm{b}}$, Jens Askov Jensen ${ }^{\mathrm{a}}$, Poul Henckel ${ }^{\mathrm{a}}$, \\ Jens Hansen-Møller ${ }^{c}$, Kostas Syriopoulos ${ }^{\mathrm{d}}$, Derek V. Byrne ${ }^{\mathrm{b}}$ \\ ${ }^{a}$ Department of Food Science, University of Aarhus, Faculty of Agricultural Sciences, Research Centre Foulum, 8830 Tjele, Denmark \\ ${ }^{\mathrm{b}}$ Department Food Science, Sensory Science, University of Copenhagen, Faculty of Life Sciences, Rolighedsvej 30, 1958 Frederiksberg C, Denmark \\ ${ }^{\mathrm{c}}$ Department of Animal Health, Welfare and Nutrition, University of Aarhus, Faculty of Agricultural Sciences, Research Centre Foulum, 8830 Tjele, Denmark \\ ${ }^{\mathrm{d}}$ Wageningen University, Animal Nutrition Group, P.O. Box 338, 6700 AH Wageningen, The Netherlands
}

\section{A R T I C L E I N F O}

\section{Article history:}

Received 22 December 2007

Received in revised form 24 April 2008

Accepted 16 May 2008

Keywords:
Chicory
Lupine
Fibre
NSP,
Boar taint
Skatole
Androstenone
Sensory profiling
Meat quality

\begin{abstract}
A B S T R A C T
Skatole, androstenone and other compounds such as indole cause boar taint in entire male pork. However, female pigs also produce skatole and indole. The purpose of this experiment was to minimise boar taint and increase overall impression of sensory quality by feeding entire male and female pigs with fibrerich feedstuffs. The pigs have been fed three organic diets for either 1 or 2 weeks prior to slaughter of which two diets contained different fermentable fibre-rich feedstuffs - 10-13.3\% dried chicory roots or $25 \%$ blue lupines. These two treatments were compared with pigs fed with an organic control diet for either 1 or 2 weeks prior to slaughter. Lupines significantly reduced skatole in blood and backfat for both genders after 1 week. Moreover, lupines showed negative impact on growth rate and feed conversion whilst chicory showed no significant differences in this respect. However, the indole concentration was significantly lower in chicory than lupine fed pigs. From a sensory perspective, chicory and lupine feeding reduced boar taint since odour and flavour of manure related to skatole and urine associated to androstenone were minimised. The level of boar taint in the entire male pigs was most effectively reduced after 14 days by both fibre-rich feeds while lupine had the largest influence on "boar" taint reduction in female pigs.
\end{abstract}

(c) 2008 Elsevier Ltd. All rights reserved.

\section{Introduction}

Boar taint is primarily caused by skatole and androstenone and other compounds such as indole (EFSA, 2004; Mortensen \& Sørensen, 1984; Patterson, 1968). Skatole is produced by both male and female pigs from the metabolism of the amino acid tryptophane in the large intestine and indole is like skatole a breakdown product of tryptophane while androstenone is a male steroid pheromone (EFSA, 2004; Zamaratskaia, 2004; Aldal et al., 2005).

Different feeds have been tested for their effect on skatole levels in the digestive tract, faeces and backfat (Claus, Lösel, Lacorn, Mentschel, \& Schenkel, 2003; Claus, Weiler, \& Herzog, 1994; Hansen et al., 2006; Jensen \& Jensen, 1998; Jensen, Cox, \& Jensen, 1995; Lösel, Lacorn, Buttner, \& Claus, 2006; Zamaratskaia, Babol, Andersson, Andersson, \& Lundström, 2005). Additions of nondigestible oligosaccharides, fructo-oligosaccharides/inulin (FOS) in the diet have been shown to decrease skatole levels in faeces, backfat and blood (Claus et al., 1994; Jensen \& Jensen, 1998). Han-

\footnotetext{
* Corresponding author. Tel.: +45 8999 1255; fax: +45 89991564

E-mail address: LauritsLydehoj.Hansen@agrsci.dk (L.L. Hansen).
}

sen et al. (2006) tested the influence of crude and dried chicory roots, which have a high content of inulin (FOS), on skatole levels in plasma and backfat. The skatole concentration in the plasma was reduced to low levels after only 3 days of feeding 25\% dried chicory roots and decreased further after 7 days and remained at a very low level until the end of the feeding period for both crude and dried chicory. The skatole equivalent in the backfat at slaughter was also very low in both crude and dried chicory fed pigs. The results for chicory fed pigs were similar to those fed purified inulin, indicating that inulin (FOS) is the main component of chicory and responsible for the skatole reduction (Hansen et al., 2006). Further, studies have demonstrated that $10 \%$ dried chicory or more in the feed significantly reduced skatole in the blood and backfat of entire male pigs after 7, 14 and 21 days of feeding. This resulted in a significant reduction in perceived boar taint, related to skatole, and thus improved the flavour and taste of meat produced from entire male pigs (Byrne \& Hansen, 2005; Hansen, 2005). Also, $25 \%$ lupine-based diet during the whole fattening period has been shown to reduce skatole levels in castrated male and female pigs (Claudi-Magnussen \& Hansen, 2005; Hansen \& Claudi-Magnussen, 2004). 
Sensory profiling, a method in which a panel uses a developed sensory vocabulary to describe perceived sensory characteristics in a sample set, has previous been applied in the evaluation of the level of boar taint (Dijksterhuis et al., 2000; Banon, Costa, Gil, \& Garrido, 2003; Byrne, Thamsborg, \& Hansen, 2007). Sensory boar taint is perceived during cooking and eating, and is described as having a distinctive and unpleasant characteristic odour and flavour (EFSA, 2004). Skatole is mostly associated with sensory descriptors such as manure and androstenone is mostly related to urine (Dijksterhuis et al., 2000). The results from a sensory profiling can be interpreted alone or in combination with for instance chemical measurements to elucidate possible underlying predictive and causal relationships.

The aim of the present study was to investigate the effect of feeding $10 \%$ dried chicory roots and $25 \%$ blue lupine seeds for 7 or 14 days prior to slaughter on skatole and indole levels in backfat as well as on sensory quality of $M$. Longissimus dorsi muscle (LD). Further, production results were registered and meat quality parameters were measured on the LD. The focus of the study was on the effect of the non-digestible oligosaccharides on skatole and indole. Thus, androstenone was not involved since a previous experiment by Hansen et al. (2006) found that feeding chicory did not affect androstenone levels except in one of three trials. However, sensory descriptors such as urine odour and flavour corresponding to androstenone were included in the sensory profiling to enable tracking of this aspect.

\section{Material and methods}

\subsection{Animals and housing}

Forty eight Danish crossbreed pigs of Duroc sires and crossbreed dam Danish Landrace $\times$ Large White (DLY) were produced at the Organic Research Station Rugballegård, Horsens, Denmark. The female and entire male pigs were kept in separate stables to avoid early sexual maturity and possibly elevated levels of androstenone in the male pigs. The pens were kept clean to avoid increased skatole and indole concentration in the subcutaneous fat (Hansen, Larsen, Jensen, Hansen-Møller, \& Bardon-Gade, 1994).

\subsection{Dietary treatments}

Before initiation of the experiment, the pigs were fed an organic certified concentrate diet according to Danish recommendation for growing pigs (Madsen, Petersen, \& Soegaard, 1990) and ad libitum clover grass silage. The experiment proper then consisted of two replicates each including 24 pigs ( 12 males and 12 females). At an avg. live weight of $90 \mathrm{~kg}$, the pigs were assigned to one of the three feeding treatments (control (CON), dried chicory (DC), lupine (LUP)) according to their initial live weight, litter and gender (Table 1 ). The pigs were weighted on day 0 , before they received the experimental diet. They were weighted again on day 7 and the heaviest from each pen was slaughtered the next day (day 8). The remaining pig was slaughtered on day 15 . The calculated live weight at slaughter (warm carcass weight $\times 1.35$ ) was between 100 and $108 \mathrm{~kg}$. Independent of the treatment, the pigs were fed with $3 \mathrm{~kg}$ per day, which is around 95\% according to the Danish scale for finishing pigs (Madsen et al., 1990). The control feeding (CON) consisted of $100 \%$ organic concentrate. For the chicory feeding (DC), the inulin-rich variety of chicory (Cichorium intybus L. var Orchies) was dried at a temperature just below $65^{\circ} \mathrm{C}$ for $48 \mathrm{~h}$. DC consisted of $10 \%$ dried chicory plus $90 \%$ organic concentrate at the first experimental replicate and $13.3 \%$ dried chicory plus $86.7 \%$ organic concentrate at the second replicate. The amount of dried chicory roots was increased from $10 \%$ to $13.3 \%$ in the DC diet in the second replicate because the level of skatole equivalents in backfat from the pigs in the first replicate was not significantly decreased compared to the control ( $\mathrm{CON})$ fed and at the same time it was found by several analyses of the dried chicory used for this experiment that it contained less fructans (inulin) (avg. around $36 \%$ ), compared to around $46 \%$ in earlier experiments. The $13.3 \%$ dried chicory in the second replicate was mixed with the pelleted control (CON) feed just before the delivery of the meal. The chicory fed pigs were not supplied with further protein as the protein requirement for finishing pigs was fulfilled (Danish Bacon \& Meat Council, 2002). The lupine feeding (LUP) consisted of $25 \%$ lupine plus $75 \%$ organic concentrate (see Table 2 ). A commercial variety of blue lupines (Lupinus angustifolius var. Prima) was used.

The three diets were conditioned shortly at $80^{\circ} \mathrm{C}$ according to the Danish regulation for destroying any possible Salmonella contamination before agglomeration. All the feeding types were provided to the pigs pelleted except from the $13.3 \%$ dried chicory in the second replicate of the experiment, which were not conditioned at $80^{\circ} \mathrm{C}$. The composition and the nutrient content of the control and the two experimental diets are presented in Table 2 .

\subsection{Slaughter procedure}

On the day of slaughter, the pigs were transported from the Organic Research Station at Rugballegård to the experimental abattoir at Research Centre Foulum $(100 \mathrm{~km})$, by a special truck for animal transportation. All pigs arrived to the abattoir of Research Centre Foulum at 8.00 a.m. after $1.5 \mathrm{~h}$ of transport from Rugballegaard. The pigs were slaughtered in two groups according to their sex (first the males) and in random order according to their treatment (diet) within the sex groups. The pigs were stunned by $85 \%$ $\mathrm{CO}_{2}$ for $3 \mathrm{~min}$, exsanguinated, scalded at $62{ }^{\circ} \mathrm{C}$ for $3 \mathrm{~min}$. Thereafter, they were cleaned and eviscerated. The whole procedure lasted $30 \mathrm{~min}$. Unchilled carcasses were split in two equal halves and placed in a room at $12^{\circ} \mathrm{C}$. One hour after exsanguination, the carcasses were placed in the chill room at $4{ }^{\circ} \mathrm{C}$, with intermittent airflow. Normally $4{ }^{\circ} \mathrm{C}$ is reached approximately in $12 \mathrm{~h}$ post-mortem

Table 1

Experimental design for the feeding period of the three treatments with organic concentrate, dried chicory and blue lupine of 1 or 2 weeks

\begin{tabular}{|c|c|c|c|c|}
\hline Replicate $^{\mathrm{a}}$ & Treatment & No. of pigs & Experimental units & Feed composition \\
\hline \multirow[t]{3}{*}{1} & Control (CON) & 8 & 4 Pens of 2 pigs $^{b}$ & $100 \%$ Organic concentrate \\
\hline & Chicory (DC) & 8 & 4 Pens of 2 pigs $^{b}$ & $90 \%$ Organic concentrate $+10 \%$ dried chicory \\
\hline & Lupine (LUP) & 8 & 4 Pens of 2 pigs $^{b}$ & $75 \%$ Organic concentrate $+25 \%$ blue lupine \\
\hline \multirow[t]{3}{*}{2} & Control (CON) & 8 & 4 Pens of 2 pigs $^{b}$ & $100 \%$ Organic concentrate \\
\hline & Chicory (DC) & 8 & 4 Pens of 2 pigs $^{b}$ & $86.7 \%$ Organic concentrate $+13.3 \%$ dried chicory \\
\hline & Lupine (LUP) & 8 & 4 Pens of 2 pigs $^{b}$ & $75 \%$ Organic concentrate $+25 \%$ blue lupine \\
\hline Total & & 48 & 24 Pens of 2 pigs & \\
\hline
\end{tabular}

${ }^{\text {a }}$ Experimental replicate 1 and replicate 2 were executed with 1 month in between each other.

b 2 pens with males +2 pens with females in gender separated stables. The heavier of the two pigs in a pen was slaughtered after a 1 week feeding period and remaining part after 2 weeks feeding period. 
Table 2

Composition and nutrient content of the control $(\mathrm{CON})$ and the experimental diets (DC and LUP)

\begin{tabular}{|c|c|c|c|}
\hline & $\mathrm{CON}$ & DC & LUP \\
\hline \multicolumn{4}{|l|}{ Composition ( $\mathrm{mg} / \mathrm{kg}$ ) } \\
\hline Dried chicory & - & 10.0 & - \\
\hline Blue lupine & - & - & 25.0 \\
\hline Soybean cake & 8.0 & 7.2 & 2.0 \\
\hline Rape seed cake & 10.0 & 9.0 & 7.0 \\
\hline Rape seed & 1.3 & 1.1 & 1.6 \\
\hline Peas & 15.0 & 13.5 & 5.0 \\
\hline Sunflower cake & 7.0 & 6.3 & 5.2 \\
\hline Wheat & 21.3 & 19.2 & 22.1 \\
\hline Barley & 10.0 & 9.0 & 10.0 \\
\hline Oat & 25.0 & 22.5 & 20.0 \\
\hline Lime stone & 1.1 & 1.0 & 1.1 \\
\hline Mono calcium phosphate & 0.7 & 0.6 & 0.4 \\
\hline Salt & 0.5 & 0.4 & 0.5 \\
\hline Vitamins and minerals & 0.2 & 0.2 & 0.2 \\
\hline Total & 100.0 & 100.0 & 100.0 \\
\hline \multicolumn{4}{|l|}{ Calculated analysis ( $\mathrm{g} / \mathrm{kg} \mathrm{DM})$} \\
\hline FUp & 1.0 & 0.99 & 0.98 \\
\hline Dry matter & 901.8 & 892.10 & 894.4 \\
\hline Crude protein $(N \times 6.25)$ & 202.2 & 183.9 & 217.4 \\
\hline Crude fat & 59.4 & 54.1 & 60.2 \\
\hline Crude fibre & 83.7 & 76.2 & 103.6 \\
\hline Ash & 61.9 & 61.1 & 58.5 \\
\hline Lysine & 10.1 & 9.2 & 9.8 \\
\hline Methionine & 3.3 & 3.0 & 2.7 \\
\hline Tryptophan & 2.4 & 2.2 & 2.3 \\
\hline
\end{tabular}

*FUp = Scandinavian feed units for pigs; $1 \mathrm{FUp}=7.38 \mathrm{MJ}$ NE.

in carcasses similar in size, meat percentage and weight, in this chill room.

\subsection{Sampling and meat quality parameters}

Blood samples were taken from the Vena vulgaris into heparinised vacuum tubes on days 0 and again just before stunning (either on day 8 or 15). Blood samples were kept on ice until transport to the laboratory. The samples were centrifuged in $2000 \mathrm{~g}$ for $20 \mathrm{~min}$ in $4{ }^{\circ} \mathrm{C}$ for plasma separation and plasma was stored in $-80^{\circ} \mathrm{C}$ until skatole and indole analysis (Hansen-Møller, 1998).

Forty-five minutes post-mortem, back-fat samples from the neck region, approximately $100 \mathrm{~g}$, were taken for determination of skatole equivalents at the Danish Crown, Ringsted, Denmark (Mortensen \& Sørensen, 1984).

Duplicate $\mathrm{pH}$ and temperature measurements were made $45 \mathrm{~min}$ and $24 \mathrm{~h}$ post-mortem in muscle M. Longissimus dorsi (LD) above the curvature of the last rib. Water-holding capacity (WHC) was measured on a slice of LD muscle, $10 \mathrm{~cm}$ from the last rib in the cranial direction as drip loss, using the plastic bag method described by Honikel (1998).

Meat colour was measured using a Minolta Chroma Meter CR300 (Osaka, Japan) on cutlets of LD. Samples were allowed to bloom for $1 \mathrm{~h}$ at $4{ }^{\circ} \mathrm{C}$ prior to measurement. Carcass lean meat percentage was predicted $24 \mathrm{~h}$ post-mortem using the Fat-O-Meter (SFK-Technologies, Denmark), based on backfat thickness of the last lumbar vertebra, $8 \mathrm{~cm}$ from the midline, and backfat and LD muscle thickness between the last third and fourth rib, $6 \mathrm{~cm}$ from the midline.

\subsection{Chemical analysis}

\subsubsection{Feed analysis}

The content of low molecular sugars in the experimental diets was determined as described by Larsson and Bengtsson (1983).

The chemical analysis for the low molecular sugars content of the four diets and the pure dried chicory showed the remarkable difference in fructans (inulin) content between the experimental diets. The dried chicory diets (10\% and $13.3 \%$ ) contained four times more fructans (inulin) than the other two diets (CON and LUP). The amount of fructans that the individual pig consumed was 26.4, $112.5,168$ and $26.7 \mathrm{~g} /$ day for CON, 10\% DC, 13.3\% DC and LUP, respectively, if we assumed that the first week each pig from the pair ate an equal amount of feed ( $3 \mathrm{~kg} / \mathrm{pig} /$ day).

\subsubsection{Glycogen determination}

The LD samples taken at the last rib above the last rib curvature, were frozen in liquid nitrogen immediately after sampling, and stored at $-80^{\circ} \mathrm{C}$ until analysis. Glycogen content was determined in a $25 \mathrm{mg} \mathrm{LD}$ sample, which was boiled with $5 \mathrm{ml}$ of $1 \mathrm{M} \mathrm{HCl}$ at $100{ }^{\circ} \mathrm{C}$ for $2 \mathrm{~h}$. The supernatant was analysed for glucose residues (Passonneau \& Lowry, 1993).

\subsubsection{Skatole and indole in plasma and skatole equivalents in backfat}

High-performance liquid chromatography (HPLC) described by Hansen-Møller (1998) wasa used to measured skatole and indole in plasma. Skatole equivalents in backfat were measured by the spectrophotometric method described by Mortensen and Sørensen (1984) at the abattoir Danish Crown, Ringsted, Denmark.

\subsection{Sensory evaluation}

\subsubsection{Selection of panellists}

The selection of panellists for profiling was carried out in accordance with ISO, 1993, 1994a, 1994b. Overall, panellists were required to display sensitivity to skatole and androstenone, (see Banon et al., 2003). The potential candidates were recruited from the public and students of University of Copenhagen, Faculty of Life Science, Frederiksberg, Denmark. The sensory panel consisted of one male and nine females in the age range 20-56 years.

\subsubsection{Sample preparation for sensory profiling}

LD was used for sensory profiling. All muscles were stored vacuum-packed in darkness at $-22^{\circ} \mathrm{C}$. Prior to cutting, muscles were held at $4{ }^{\circ} \mathrm{C}$ for approximately $12 \mathrm{~h}$ to ease slicing $(1 \mathrm{~cm}$ thickness). Due to the limited length of the LDs (approximately $23 \mathrm{~cm}$ ), each chop was halved. Individual chops were subsequently vacuumpacked in oxygen impermeable plastic laminate bags and stored at $-22^{\circ} \mathrm{C}$ for up to 1 week before the sensory profiling. Prior to the sensory profiling, the chops were thawed and subsequently removed from their vacuum bags for oven-cooking at $150{ }^{\circ} \mathrm{C}$ for 3 min a side. The samples were immediately served to the panellists. The average internal serving temperature was $68^{\circ} \mathrm{C}$.

\subsubsection{Descriptive sensory vocabulary development and profiling}

Prior to the sensory profiling, the sensory panel developed a sensory vocabulary (Table 3 ) to describe and discriminate the pork samples, sensory characteristics (see Byrne, Bak, Bredie, Bertelsen, \& Martens, 1999; Byrne, O'Sullivan, Dijksterhuis, Bredie, \& Martens, 2001). The sensory work was carried out in the sensory laboratory at the University of Copenhagen, Faculty of Life Science, Frederiksberg, Denmark, which fulfilled requirements according to the international standards (ASTM, 1986; ISO, 1988). The descriptors were pre-developed from a previous paper by Byrne et al. (2007) and supported by an expert pre-tasting. A $150 \mathrm{~mm}$ unstructured line scale anchored on the left by the word 'none' and on the right with 'very much' was used (Meilgaard, Civille, \& Carr, 2006). The panel performance was evaluated by PanelCheck 1.2.1 (MATFORSK, Norway). The training sessions took place over 4 days, each of $2 \mathrm{~h}$.

The sensory descriptive profiling sessions, each of $2 \mathrm{~h}$, were carried out over 4 days. Each sensory profiling was carried out by the same sensory panel as utilised in vocabulary development. The 
Table 3

List of the 17 sensory descriptors and an acceptability question with definitions derived for the sensory profiling of the pork samples of the three treatments with organic concentrate, dried chicory and blue lupine for 1 or 2 weeks prior to slaughter ${ }^{\mathrm{a}}$

\begin{tabular}{|c|c|c|}
\hline & Term & Definition with reference materials \\
\hline & Odour & Odour associated with \\
\hline 1 & Fresh_cooked_pork_meat-O (frisk stegt svinekød) & Oven-cooked pork meat with no surface browning \\
\hline 2 & Boiled_broiler-O (kogt fjerkræ) & Extract from boiled broiler \\
\hline 3 & Stable/piggy-O (stald/dyr) & $1: 1$ solution of mixture of skatole $(50 \mu \mathrm{g} / \mathrm{g})$ and androstenone $(200 \mu \mathrm{g} / \mathrm{g})$ \\
\hline 4 & Urine-O (urin) & Pure androstenone \\
\hline 5 & Manure-O (gødning) & Pure skatole \\
\hline \multirow[t]{2}{*}{6} & Sweat-O (sved) & Cooked pork meat from entire male pigs smelling like sweat, based on the perception of androstenone \\
\hline & Flavour & Aromatic taste sensation associated with \\
\hline 7 & Fresh_cooked_pork_meat-F (frisk stegt svinekød) & Oven-cooked pork meat with no surface browning \\
\hline 8 & Boiled_broiler-F (kogt fjerkræ) & Extract from boiled broiler \\
\hline 9 & Fresh_sour-F (frisk syrlig) & Mixture of Greek yoghurt and natural yoghurt 1:1 \\
\hline 10 & Stable/piggy-F (stald/dyr) & $1: 1$ solution of mixture of skatole $(50 \mu \mathrm{g} / \mathrm{g})$ and androstenone $(200 \mu \mathrm{g} / \mathrm{g})$ \\
\hline 11 & Urine-F (urin) & Pure androstenone. Reference presented for assessment aim to allow it to evoke 'flavour' \\
\hline 12 & Manure-F (gødning) & Pure skatole. Reference presented for assessment aim to allow it to evoke 'flavour' \\
\hline \multirow[t]{2}{*}{13} & Sweat-F (sved) & Cooked pork meat from entire male pigs smellling like sweat, based on the perception of androstenone \\
\hline & Taste & Taste associated with \\
\hline 14 & Sweet-T (sød) & Diluted solution of sucrose \\
\hline \multirow[t]{2}{*}{15} & Bitter-T (bitter) & Diluted solution of quinine chloride \\
\hline & After taste & Aftertaste sensation associated with: \\
\hline 16 & Bitter-AT (bitter) & Bitter aftertaste from bitter solution of quinine chloride \\
\hline \multirow[t]{2}{*}{17} & Sweet-AT (sød) & Sweet aftertaste from sweet solution of sucrose \\
\hline & Overall evaluation & Preference \\
\hline 18 & Overall impression (overordnet indtryk) & The liking of the sample \\
\hline
\end{tabular}

a The Danish term is used in parenthesis; there may be small differences with the English translation. Suffix to sensory terms indicates method of assessment by panellists: O; odour, F; flavour, T; taste, AT; after taste.

sample sets contained all the feeding treatments (48 combinations) and were assessed in duplicate by each of the 10 panellists giving 24 samples per sessions. The sample presentation to the individual panellists on each day of profiling was in randomised order. The quantitative data was collected using the FIZZ Network data acquisition software version 2.20B (BIOSYSTEMS, Couternon, France).

\subsection{Data analysis}

Due to the fact that the pigs were housed in pairs and the feed consumption was registered for the pair, each pair was considered as one experimental unit. The production and meat quality results for each experimental unit were calculated as the average of the results of the individual pigs of the pair. All the data were analysed with the Statistical Analysis System version 9.1 (SAS Institute, Cary, NC, USA). The GLM procedure was used to calculate the leastsquares means and the standard error of the means for the production and meat quality attributes results. The GLM model included the fixed effect of treatment (diet), gender replicate and the interactions between treatment and gender and treatment and replicate. For live weight at slaughter and daily gain, the initial live weight was used as covariate. For the variable of lean meat percentage the warm carcass weight were used as covariate. For skatole and indole in plasma and skatole equivalents in backfat at slaughter, skatole and indole at day 0 were used as covariate.

In order to see the effect of feeding 7 or 14 days before slaughter on boar taint variables (skatole and indole in plasma as well as sensory attributes, etc.), it was assumed that the pigs in the same pen ate equal amounts of feed during the first week and the results for the individual pig were used. The GLM model included the fixed effect of treatment (diet), gender, replicate, feeding time (7 or 14 days) and the interaction between gender and treatment and between treatment and feeding time. The results are presented as least square means and standard error. Significant difference were tested for $P$-value $<0.05$.

Generalised procrustes analysis (GPA) (Gower, 1975) was performed on the sensory raw data using Matlab 6.5 (MathWorks
Inc., USA) to correct for the panellist effects in line scale usage. Subsequent multivariate analyses were performed using the Unscrambler Software, Version 9.7 (CAMO ASA, Trondheim, Norway). Quantitative ANOVA partial least-squares regression (APLSR) was performed to visualize and determine the descriptive ability of the sensory profiling data sets for the feeding treatments. Terms close together are related and terms far away from each other are different. PC1 is the main source of variation and PC2 is the next most important source of variation etc. Data was averaged over panellists and sensory replicates. The $Y$-matrix containing the level of scale use corrected sensory data and the concentration of skatole was weighted by $1 /$ sdev and fully cross-validated. To derive significant indications, regression coefficients were analysed by jack-knifing, which is based on cross-validation (Martens \& Martens, 2001). The same tendencies were found for the two experimental replicates. Thus, the results will be shown for the two experimental replicates together. However, the sensory results are separately presented for each gender.

\section{Results}

\subsection{Animal production}

The production results between the control (CON) and dried chicory (DC) fed pigs did not significantly differ but the lupine treatment showed lower production. The daily gain of the control ( $951 \mathrm{~g} /$ day) and chicory (912 g/day) fed pigs were similar but the lupine (LUP) group $(720 \mathrm{~g} /$ day $)$ tended to grow less $(P=0.107)$. Consequently, the LUP fed pigs showed higher FCR (feed conversion ratio) (4.4 versus 3.29 and $3.36 \mathrm{~kg} / \mathrm{kg}$ ) than for the CON and DC group, respectively, $(P<0.05)$ and FUp per $\mathrm{kg}$ gain $(4.31$ versus 3.29 and 3.32) than for the CON and DC group, respectively, $(P<0.05)$ (Scandinavian feed units pigs; $1 \mathrm{FUp}=7.38 \mathrm{MJ}$ NE.). Live weight at slaughter, warm and cold carcass weight tended to be lower in the LUP treatment $(p<0.10)$. E.g. warm carcass weight $77.7,77.3$, and $75.9 \mathrm{~kg}$ for the CON, DC and LUP group, respectively. However, lean meat percentage was not influenced by the treat- 
ments corrected to same warm carcass weight $(61.4 \%, 61.6 \%$, and $61.8 \%$ for the CON, DC and LUP group, respectively, $P=\mathrm{ns}$ ).

\subsection{Technological parameters}

In Table 4, the results of the meat quality analyses are shown. The glycogen contents were significantly higher for the LUP compared to DC fed pigs $(P<0.05)$. The DC fed pigs had the lowest glycogen content but did not significantly differ from the CON group. $\mathrm{pH}$ and temperature $45 \mathrm{~min}$ and $24 \mathrm{~h}$ post-mortem, colour and drip loss did not significantly differ between the feeding treatments.

Significant differences were found between genders. Entire male pigs had lower $\mathrm{pH}_{45} \mathrm{~min}$, which approached significance $(P<0.1)$, but significantly $(P<0.001)$ higher ultimate $\mathrm{pH}$. The carcass temperature $24 \mathrm{~h}$ post-mortem was significantly higher $(P<0.001)$ in the entire male pigs. The glycogen content was significantly higher $(P<0.05)$ in female pigs $45 \mathrm{~min}$ post-mortem compared to entire male pigs but $24 \mathrm{~h}$ post-mortem did not differ significantly between the two genders. Male pigs had significantly $(P<0.05)$ darker meat $\left(L^{*}\right.$-value $)$.

\subsection{Skatole and indole levels in plasma and backfat}

Skatole and indole concentrations in plasma were equal for the pigs at the initiation of the experiment (Table 4). There were no interactions between gender and treatment for skatole concentration in plasma and skatole equivalents in backfat. Feeding DC did not lower significantly the skatole concentration in plasma and the skatole equivalents in backfat after both one and two weeks feeding time. However, the LUP fed pigs had highly significantly lower skatole concentration in plasma and skatole equivalents in backfat at slaughter after both one and two weeks feeding time $(P<0.001)$. At the beginning of the experiment, a tendency towards a significant difference $(P<0.1)$ in skatole concentration in plasma between the two genders was found with the males having the highest level. At slaughter, skatole levels in plasma were significantly $(P<0.05)$ higher in the males. The indole concentration in plasma at slaughter did not differ between the CON and the tested diets but there was a significant difference $(P<0.05)$ between LUP and DC treatment with the DC having the lowest level (Table 4).

The controls had the highest numeric skatole equivalents in backfat (Fig. 1) followed by the DC and LUP group for both genders. However, there was no significant difference between the CON and DC group in both day 7 and day 14 of feeding. Averaged over genders, the skatole concentration in backfat for the LUP fed pigs were significantly lower than the CON $(P<0.01)$ and the DC fed $(P<0.01)$. The two genders differed significantly in skatole levels in backfat as entire male pigs had higher levels than female pigs $(P<0.05)$.

There was no interaction between treatment and feeding periods (Table 4). The CON and DC fed pigs did not significantly differ, irrespectively the treatment and feeding periods ( 7 or 14 days). The LUP group had lower skatole levels in plasma and backfat compared to the DC and CON group after 7 days $(P<0.01)$ but differed significantly only from the CON group the second week of feeding $(P<0.01)$.

There was an excellent correlation between skatole in backfat and plasma at slaughter $(r=0.94 ; P<0.0001)$.

\subsection{Sensory boar taint reduction in entire male pigs}

With respect to the entire male pigs, both feeding days and feeding types were well-described from a sensory perspective meaning that both of these are important in regards to the level of boar taint (Fig. 2). However, the feeding days prior to slaughter had relative to the feeding types the greatest importance with respect to the reduction of the level of boar taint. It was revealed since the feeding days prior to slaughter was described across

Table 4

Meat quality attributes $45 \mathrm{~min}$ and $24 \mathrm{~h}$ post-mortem and skatole and indole concentrations in plasma and skatole equivalents in backfat for the three treatments (CON, DC and LUP) and two genders (male and female pigs)

\begin{tabular}{|c|c|c|c|c|c|c|c|c|c|}
\hline & CON & DC & LUP & s.e. & $\begin{array}{l}\text { Significance } \\
\text { of treatment }\end{array}$ & Males & Females & s.e. & $\begin{array}{l}\text { Significance } \\
\text { of gender }\end{array}$ \\
\hline \multicolumn{10}{|l|}{45 min post-mortem } \\
\hline $\mathrm{pH}$ & 6.49 & 6.44 & 6.52 & 0.03 & ns & 6.45 & 6.52 & 0.03 & (") \\
\hline Temperature $\left({ }^{\circ} \mathrm{C}\right)$ & 36.9 & 36.9 & 37.6 & 0.3 & ns & 37.4 & 37.0 & 0.2 & Ns \\
\hline Glycogen ( $\mu \mathrm{mol} / \mathrm{g}$ wet muscle) & $41.51^{\mathrm{ab}}$ & $38.84^{\mathrm{a}}$ & $46.71^{\mathrm{b}}$ & 1.83 & ** & 39.2 & 45.5 & 2.0 & \\
\hline \multicolumn{10}{|l|}{$24 \mathrm{~h}$ post-mortem } \\
\hline $\mathrm{pH}$ & 5.63 & 5.63 & 5.61 & 0.02 & ns & 5.67 & 5.57 & 0.03 & ** \\
\hline Temperature $\left({ }^{\circ} \mathrm{C}\right)$ & 3.42 & 3.36 & 3.38 & 0.03 & ns & 3.46 & 3.31 & 0.03 & ${ }^{* *}$ \\
\hline Glycogen ( $\mu \mathrm{mol} / \mathrm{g}$ wet muscle) & $25.39^{\text {cd }}$ & $23.66^{c}$ & $29.65^{d}$ & 1.38 & ** & 24.96 & 27.51 & 1.13 & Ns \\
\hline \multicolumn{10}{|l|}{ Colour } \\
\hline$L^{*}$ & 55.97 & 57.48 & 57.09 & 0.58 & ns & 55.7 & 58.0 & 0.5 & $* * *$ \\
\hline$a^{*}$ & 7.37 & 7.6 & 7.65 & 0.22 & ns & 7.75 & 7.33 & 0.18 & Ns \\
\hline$b^{*}$ & 5.6 & 6.2 & 6.07 & 0.22 & ns & 5.80 & 6.12 & 0.18 & Ns \\
\hline Drip loss (\%) & 3.83 & 3.73 & 3.35 & 0.33 & ns & 3.46 & 3.81 & 0.27 & Ns \\
\hline \multicolumn{10}{|l|}{ Skatole in plasma $(\mu \mathrm{g} / \mathrm{l})$} \\
\hline Day 0 & 1.87 & 1.95 & 2.00 & 0.22 & ns & 2.18 & 1.70 & 0.18 & $\left({ }^{*}\right)$ \\
\hline 7 days & $2.24^{\mathrm{a}}$ & $2.25^{\mathrm{a}}$ & $0.63^{\mathrm{b}}$ & 0.38 & ** & - & - & - & - \\
\hline 14 days & $2.56^{\mathrm{d}}$ & $1.65^{\mathrm{dc}}$ & $0.28^{\mathrm{c}}$ & 0.38 & ${ }^{* *}$ & - & - & - & - \\
\hline At slaughter ${ }^{\mathrm{a}}$ & $2.43^{\mathrm{b}}$ & $1.95^{\mathrm{b}}$ & $0.43^{\mathrm{a}}$ & 0.31 & ${ }^{* * *}$ & 2.03 & 1.17 & 0.25 & ** \\
\hline \multicolumn{10}{|l|}{ Skatole in backfat $(\mu \mathrm{g} / \mathrm{g})$} \\
\hline 7 days & $0.12^{\mathrm{e}}$ & $0.12^{\mathrm{e}}$ & $0.04^{\mathrm{f}}$ & 0.02 & $* *$ & - & - & - & - \\
\hline 14 days & $0.14^{\mathrm{g}}$ & $0.10^{\text {gh }}$ & $0.03^{\mathrm{h}}$ & 0.02 & ** & - & - & - & - \\
\hline \multicolumn{10}{|l|}{ Indole in plasma $(\mu \mathrm{g} / \mathrm{l})$} \\
\hline Day 0 & 0.51 & 0.70 & 0.67 & 0.13 & ns & 0.64 & 0.61 & 0.11 & Ns \\
\hline At slaughter ${ }^{\mathrm{a}}$ & $0.64^{\mathrm{dc}}$ & $0.50^{\mathrm{c}}$ & $0.97^{\mathrm{d}}$ & 0.14 & ** & 0.78 & 0.62 & 0.10 & Ns \\
\hline
\end{tabular}

$\overline{\mathrm{a}, \mathrm{b}, \mathrm{c}, \mathrm{d}}$ Least-squares means that do not share a common superscript letter, within the row, differ significantly $(P<0.05) .\left(^{*}\right), P<0.1,{ }^{*} ; P<0.05,{ }^{* *} ; P<0.01,{ }^{* * *} ; P<0.001$, ns; nonsignificant. There was no interaction between treatment and gender, treatment and replicate, and treatment and feeding days.

a Average of 7 days and 14 days. 


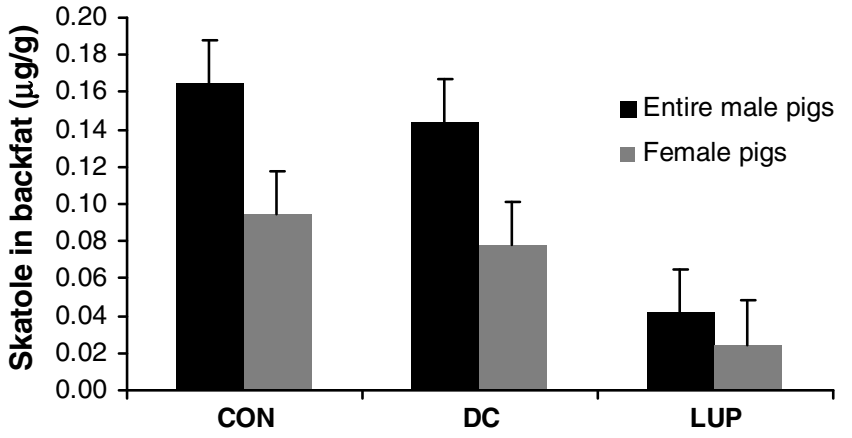

Fig. 1. Skatole equivalents in backfat ( $\mu \mathrm{g} / \mathrm{g}$ fat) (least-square means \pm standard error) for entire male and female pig for the three treatments (CON, DC and LUP) averaged over feeding days.

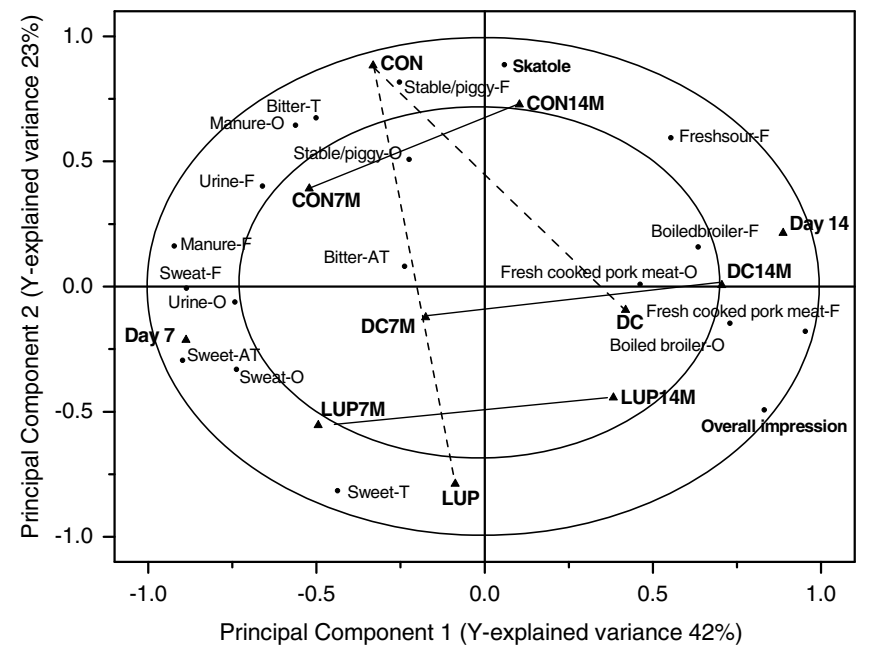

Fig. 2. Male; APLSR correlation loadings plot of PC1 versus PC2. The design variables: feeding types; CON, DC and LUP, and feeding days prior to slaughter; 7 and 14 in the $X$-matrix and the sensory terms and skatole levels in the $Y$-matrix. O; odour, F; flavour, T; taste, AT; aftertaste. The horizontal arrows highlight the effect of the feeding period prior to slaughter while the dashed vertical arrows illustrate the differences in the feeding types in relation to the control feeding.

PC1. A systematic effect of the feeding days was observed for all the feeding types moving from the boar taint related sensory terms to fresh_cooked_pork-O/F (odour/flavour), boiled_broiler-O/F, fresh_sour-F and overall impression (Fig. 2). The reduction of boar taint was greatest for 14 days of feeding with both DC and LUP compared to 7 days of feeding. This was clear as 14 days was significantly positively correlated to fresh_cooked_pork_meat-O/F $(P<0.001)$, boiled_broiler-O/F $(P<0.001)$, fresh_sour-F $(P<0.001)$ and overall_impression $(P<0.001)$ while 7 days of feeding was positively correlated to taint descriptors urine- $\mathrm{O} / \mathrm{F}(P<0.001)$, manure-O $(P<0.01)$, manure-F $(P<0.001)$, sweat-O/F $(P<0.001)$ and to sweet-T/AT $(P<0.001)$.

Differences between the feeding types were observed. CON feeding was significantly positively correlated to stable/piggy-O/F $(P<0.001)$, manure-O $(P<0.001)$, fresh_sour-F $(P<0.01)$, bitter-T $(P<0.001)$, urine-F $(P<0.001)$, manure-F $(P<0.01)$ and sweat-F $(P<0.05)$. By comparing the DC feeding and the LUP feeding with the CON feeding, it was found that DC and LUP both were able to reduce the level of boar taint significantly for a number of key descriptors. In that the LUP and DC samples were moving away from the boar taint related sensory terms. Both DC and LUP were significantly positively correlated to the overall_impression $(P<0.001)$. Further, DC resulted in significantly positive correlation with fresh_cooked_pork_meat-O $\quad(P<0.01)$, boiled_broiler-O $(P<0.001)$, fresh_cooked_pork_meat-F $(P<0.001)$, and boiled_broiler-F $(P<0.05)$ while LUP resulted in significantly positive correlation to sweet-T $(P<0.001)$ and sweet-AT $(P<0.05)$.

In addition, the measurements of skatole equivalents in the backfat were included in the data analysis. High levels of skatole equivalents in the pork meat were significantly $(P<0.001)$ positively correlated to the CON feeding and the sensory descriptor stable/piggy. When feeding with DC or LUP the level of skatole equivalents in the backfat decreased. However, only LUP was significantly $(P<0.001)$ negatively correlated to skatole equivalents.

\subsection{Sensory "boar" taint reduction in female pigs}

In contrast to the entire male pigs, the main variation among the female pigs was explained by the feeding treatments (Fig. 3). The CON feeding was significantly positively correlated to the boar taint descriptors urine-O $(P<0.01)$, manure-O $(P<0.001)$, urine-F $(P<0.001)$ and significantly negatively correlated to the overall_impression $(P<0.001)$ but the CON feeding was also significantly positively correlated to fresh_cooked_pork_meat- $O$ $(P<0.001)$ and bitter-AT $(P<0.001)$. A reduction of "boar" taint descriptors by both DC and LUP feeding was observed involving similar sensory changes to those found in the entire male pigs. LUP or DC diet moved the meat samples towards more positive notes such as boiled_broiler-O/F, sweet-T/AT and overall impression. However, the reduction of "boar" taint descriptors was greater when feeding with LUP relative to DC. Feeding with DC resulted in significantly positive correlations with manure-O $(P<0.05)$ and bitter-AT $(P<0.05)$ and significantly negative correlation to the overall_impression $(P<0.05)$. Thus, DC resulted in bitter aftertaste and was insufficient for complete elimination of "boar" taint caused by skatole since the female samples were positively correlated to the odour of manure. LUP was significantly positively correlated to boiled_broiler-O, fresh_cooked_pork_meat-F $(P<0.01)$, boiled_broiler-F $\quad(P<0.01)$, sweet-T $\quad(P<0.001)$, sweet-AT $(P<0.05)$ and overall impression $(P<0.001)$. This indicates that LUP resulted in sweet pork meat, which was positively correlated to the overall impression.

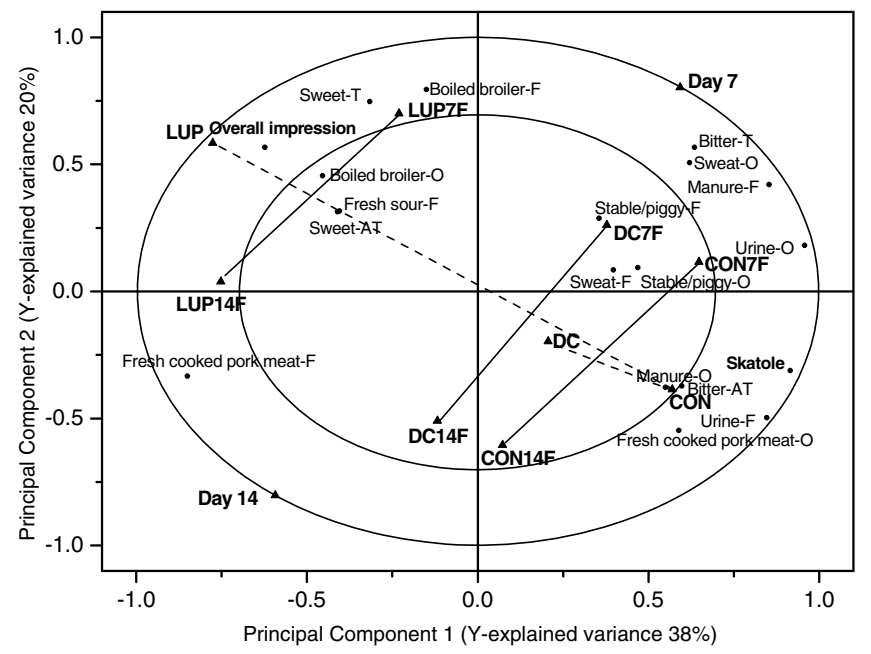

Fig. 3. Female; APLSR correlation loadings plot of PC1 versus $P C 2$. The design variables: feeding types; CON, DC and LUP, and feeding days prior to slaughter; 7 and 14 in the $X$-matrix and the sensory terms and skatole levels in the $Y$-matrix. O; odour, F; flavour, T; taste, AT; aftertaste. The arrows highlight the effect of the feeding period prior to slaughter while the dashed arrows illustrate the differences in the feeding types in relation to the control feeding. 
Only small differences were found between the two different feeding periods. Of note in female pigs was that 14 days had very little additional effect in boar taint reduction when compared to 7 days feeding. Thus, 7 days of feeding was sufficient to reduce the skatole aspect to zero in females and an additional 7 days was not needed.

\section{Discussion}

\subsection{Production and technological meat quality}

The addition of 25\% LUP in the diet had a negative effect on pig performance (growth rate and feed conversion) possibly due to anti-nutritional factors. This is in accordance to results of Fernandez and Danielsen (2006) who by inclusion of $12.5 \%$ lupines (same variety, Prima) observed no affect on performance whereas they by inclusion of $25 \%$ observed a negative effect. The authors concluded that if less than $15 \%$ of LUP was added to the diet the negative effects of the supplementation on performance could be avoided.

The glycogen content was the only parameter that was significantly affected by the feeding types. However, this difference did not seem to affect the ultimate $\mathrm{pH}$ and drip loss. No significant differences in colour were observed for the difference feeding types. But the entire male pigs had a significantly darker colour than the females. They also display a higher ultimate $\mathrm{pH}$, which may have contributed to the darker colour.

\subsection{Chemical boar taint reduction}

The effect of DC and LUP differed in reduction of skatole in plasma and backfat. It was demonstrated that feeding $10 \%$ or $13.3 \%$ DC for 1 or 2 weeks prior to slaughter did not significantly reduce skatole levels in backfat. This is in contrast to Claus et al. (1994) and Jensen and Jensen (1998) who have shown that inclusion of purified inulin or fructo-oligosacharides (FOS) reduce skatole level in backfat. Recently Hansen et al. (2006) in a precursor work to the present study demonstrated that substituting $25 \%$ of the daily energy intake with dried or crude chicory root significantly reduced skatole levels in backfat and plasma. The skatole level was significantly reduced after 1 week of feeding dried chicory and remained low with dried or crude chicory roots until the end of the experimental periods. The same reductions on skatole in plasma and backfat were obtained when substituting $14 \%$ of the daily energy intake with purified inulin (corresponds to the amount of inulin in $25 \%$ dried chicory). Hansen (2005) feeding $2.5 \%, 5 \%, 10 \%$, and $20 \%$ of dried chicory for 7,14 or 21 days before slaughter demonstrated that skatole levels in blood and backfat decreased significantly from the first week for 10 and $20 \%$ dried chicory and remained low until the end of the experiment. At the use of $20 \%$ dried chicory skatole levels were decreased more than $10 \%$. It is thus surprising that we in the present study feeding 10 or $13.3 \%$ dried chicory did not observe significantly reduced skatole concentrations in the backfat and plasma although a trend towards reduced levels of sensory skatole was observed.

In the production of the feed, the dried chicory was produced in two lots. Technical problems during the production of one of the lots implied a drying temperature $15^{\circ} \mathrm{C}$ above the recommended value below $65^{\circ} \mathrm{C}$. Chemical analysis of the lots showed that in the high temperature dried chicory $\left(80^{\circ} \mathrm{C}\right)$ the amount of inulin (fructans) was lower (around 36\%) compared to the dried chicory from previous experiments (around 46\%) and the amounts of low molecular sugars (glucose and fructose) were increased (fructose from around $1.0-5.5 \%$ ) all in comparison to the other dried lot of the same chicory root crop, which had the expected $46 \%$ fructans and low percentage of low molecular sugars as in earlier studies with dried chicory. For some reason this lot by mistake could have been used in the present experiment. Our results certainly emphasises the importance of temperature and time for drying during processing for maintaining the activity of bioactive compounds.

Secondly, it has been thought that the included yellow peas in the chicory diet may have some increasing influence on the skatole level. The amount of yellow peas in the dried chicory and control diets was $13.5 \%$ and $15 \%$ whereas in the lupine diet it was $5 \%$. Yellow peas have been shown to elevate the skatole level in backfat but only in one study by Lundström et al. (1994). However, the concentration of skatole in blood and skatole equivalents in backfat in the control and chicory treatments in this study were not high compared to earlier studies, which is also demonstrated by the initial plasma skatole concentrations before the experiment started, as we know that skatole levels traditionally increase in the weight range from 90 to $104 \mathrm{~kg}$ live weight in entire male pigs due to increasing sexual maturity. Therefore the "missing" effect of dried chicory must have other reasons than undigested trytophane from the peas (or other protein sources) in the colon to produce more skatole as found by Lundström et al. (1994).

With respect to inclusion of $25 \%$ lupines, these reduced skatole in the backfat to very low levels from the first week of feeding and remained low until the end of the second week of feeding. These observations are similar with those of Hansen and Claudi-Magnussen (2004) who found that $25 \%$ lupines reduced the skatole equivalent in backfat in castrated male and female pigs when fed lupines during the whole growth period. Jensen and Jensen (1998) found similar results with entire male pigs. Blue lupines have a high content of soluble none starch polysaccharides (NSP) and oligosaccharides (Fernadez \& Batterham, 1995), which can be used as energy source for the microbes in the large intestine. Inclusion of fermentable carbohydrates in the diet results in a change from protein to carbohydrate fermentation and through that a decreased production of off-odour compounds such as skatole and $p$-cresol (Jensen \& Hansen, 2006; Rideout, Fan, Cant, Wagner-Riddle, \& Stonehouse, 2004) and a shift from ammonia (N) excretion to microbial protein in faeces (Canh, Verstegen, Aarnink, \& Schrama, 1997; Nahm, 2003).

\subsection{Sensory boar taint reduction}

The effect of the feeding types versus the feeding days prior to slaughter with respect to lowering the level of sensory assessed boar taint differed between the pig genders. Feeding for 14 days was of greatest importance for the entire male pigs while feeding with lupine had greatest influence on the female pigs. Specifically for the entire male pigs, 14 days of chicory or lupine feeding reduced the level of boar taint more efficiently/quantitatively than 7 days of feeding. This was not the case for the female pigs where the "boar" taint levels were reduced already after just 7 days so that additional feeding days appeared not to add to this effect sufficiently. It is most likely explained by the fact that the female pigs were low in taint to begin with and the skatole related reduction was to such a degree that they were undetectable from a sensory perspective after 7 days feeding. This was in contrast to the entire male pigs where additional days of feeding had a corresponding elevated influence in terms of reduction of boar taint. This being most likely explained by the much higher levels of taint compounds related to skatole and androstenone to begin with in the entire male pigs. To give context to the different sensory effects in male and female pigs, sensory androstenone requires discussion even if the focus of the present work was on the sensory quality in relation to skatole and indole. The influence of sensory androstenone is also illustrated by Fig. 2 in which a separation of the sensory terms sweat and urine related to androstenone and the 
sensory terms manure and stable/piggy related to skatole was found. Since androstenone is a male steroid pheromone, androstenone only gains relevance for entire male pigs. The "boar" taint in the female pigs is therefore only present as a result of skatole and indole production in the GI tract. Chicory and lupine were assumed to mainly affect the skatole aspect due to their effect on the skatole production across the digestive tract since diets with high content of fermentable carbohydrates have been shown to reduce the production of skatole and p-cresol (Jensen \& Hansen, 2006). Thus, the feeding treatments were not expected to affect the level of sensory androstenone. Lupine significantly reduced the "boar" taint perception in the female pigs while chicory was insufficient for complete elimination of "boar" taint since the female samples were positively correlated to the odour of manure and skatole in backfat at slaughter. A study by Byrne et al. (2007) has previously indicated a reduction of the level of "boar" taint by $25 \%$ chicory feeding in female pigs. In the present study with respect to the entire male pigs, the perception of androstenone appeared also possibly to be affected by feeding with chicory or lupine since the urine odour and flavour were significantly reduced after 14 days feeding. Furthermore, chicory was significantly negatively correlated to sweat odour and flavour (Fig. 2). This finding is confirmed by Byrne et al. (2007) who state that a significant decrease was found in plasma androstenone with 9 weeks feeding with chicory a corresponding decrease in sweat odour. Furthermore, it has been reported that dietary fibre is capable of reducing the level of cholesterol in serum (Marlett et al., 1994; Byrne et al., 2007). As androstenone and cholesterol follow the same biosynthetic pathway, a prolonged feeding period with a dietary fibre such as chicory and lupine may be postulated as able to affect the androstenone content in plasma in a similar manner to cholesterol (Hansen et al., 2006). As female pigs do not contain androstenone, the results of the lupine female pigs show that skatole is reduced after 7 days of feeding. The sensory results of the entire male pigs indicated that sensory androstenone in interaction with the perceived sensory skatole contribute to the perception of boar taint after 7 days of feeding but after 14 days both sensory androstenone and skatole were reduced by lupine and chicory feeding.

The effect of chicory and lupine did not lead to other off-flavours in the meat. A thought was that the bitter nature of chicory roots resulted in an off-flavour. However, it was proved not to be the case since chicory was significantly positively correlated to fresh_cooked_pork_meat-O/F, boiled_broiler-O/F and overall impression. This observation is in accordance to the findings by Byrne et al. (2007). Thus, elevated levels of chicory derived bitter compounds such as sesquiterpene lactones were not determined to cause negative sensory effects (Bais \& Ravishankar, 2001). Lupine resulted in meat with sweet taste and after taste observed for both genders. This is in agreement with a previous study by Claudi-Magnussen and Hansen (2005) who found that lupines resulted in meat with sweet characteristic. Since lupines consists of $7-15 \%$ galacto-oligosaccharides ( Martínez-Villaluenga, Frías, \& Vidal-Valverde, 2005), the sweet taste in the pork meat could possibly be derived from these compounds.

The overall impression of sensory quality of the different feeding types differed among the gender of the pigs. In regards to the entire male pigs both chicory and lupine were significantly positively correlated to the overall impression at 14 days feeding. However, the chicory was closer correlated to the overall impression than the lupine. When observing the female pigs, only lupines were significantly positively correlated to the overall impression. This, indicate that the final decision of using chicory or lupine may depend on feeding time as well as gender of the pig and the desire of the sensory characteristics of the meat product e.g. as earlier mentioned lupine was characterised as having a sweet taste and after taste.

\subsection{Sensory and chemical compatibility in measuring boar taint}

The sensory results showed that both chicory and lupine had a reducing effect on boar taint after 14 days feeding time. The finding for lupine was in agreement with the chemical results, which confirmed that lupine lowered the skatole equivalent in the backfat and skatole concentration in plasma. However, the skatole was significantly reduced after 7 days but as previous discussed sensory androstenone may have contributed to the perception of boar taint since the sensory boar taint was not sufficiently lowered after 7 days. The significant reducing effect of boar taint by chicory found in the sensory analysis was not reflected by the chemical analysis of skatole. However, the chemical analysis showed a minor but not significant reduction of skatole for chicory compared with the control feeding. The indole concentration was significantly lowered after feeding with chicory compared to lupine. Even though the threshold is very low for indole (EFSA, 2004), the reason for the minimising sensory boar taint perception after feeding with chicory could be a result of the chicory effect on indole. However, it was found that chicory reduced boar taint to a greater extent than that determined by chemical analyses of skatole. It could be explained by small differences in flavour active compounds. So even though chemical analyses did not result in significant differences in flavour active compounds, these can be found to be highly significant in their effects evaluated by a trained panel due to high levels of panel sensitivity and potency of compounds. This may also explain the discrepancy in the importance of the feeding days when comparing the sensory results with the chemical results, which showed that no significant differences were found between 7 days and 14 days of feeding. This is a very important distinction to be aware of and of note is that ultimately boar taint is a sensory phenomenon thus sensory analysis must be considered the benchmark in terms of ultimate conclusions on feeding regime effects in relation to taint. Of course measuring androstenone and liver metabolism in the entire male pigs might be an issue for the future if financial support could be obtained.

\section{Conclusions and implications}

Only $25 \%$ lupine in the diet significantly reduced chemically measured boar taint in the form of skatole in backfat and plasma compared to the control feeding after 7 or 14 days feeding prior to slaughter. However, from a sensory perspective, chicory and lupine both reduced boar taint since odour and flavour of manure related to skatole and urine associated to androstenone were minimised. Sensory profiling revealed 14 days of feeding with dried chicory or lupine reduced the level of boar taint in the entire male pigs more efficiently than 7 days of feeding. "Boar" taint reduction in the female pigs was mainly reduced by lupine. Final sensory characteristics of the pork meat differed to a degree with lupine perceived as sweet. Since $25 \%$ of lupine had a negative effect on animal production parameters, the importance of sensory effect versus production results has to be considered before implementation of the feeding strategies in practice. However, both lupine and chicory feeding are suitable as a basis for a strategy to control boar taint since 14 days of feeding with either chicory or lupine showed to be suitable to increase the overall sensory quality and decrease boar taint to acceptable levels. Future studies may focus on combined use of dried chicory roots and blue lupines (no more than $15 \%$ lupine) as this is postulated to affect the total carbohydrate fermentation pattern in the intestine in a positive way and by that decrease intestine infections more effectively and possibly increase meat quality results in entire male and female pigs without decreased production. Focus on drying time and temperature on fructan quality (inulin) and feed structure of dried chicory roots and 
other fibre-rich feed components is an important issue to study for maintaining the activity of bioactive compounds.

\section{Acknowledgements}

We wish to thank all persons who were involved in crop production, animal care and laboratory analyses for their skilful technical and scientific assistance. Furthermore the support from the Danish Research Centre for Organic Farming (DARCOF) is muchappreciated (projects PRE-QEMP/QEMP).

\section{References}

Aldal, I., Andresen, Ø., Egeli, A. N., Haugen, J.- E., Grødum, A., Fjetland, O., et al. (2005). Levels of androstenone and skatole and the occurrence of boar taint in fat from young boars. Livestock Production Science, 95, 121-129.

ASTM (1986). Physical requirements. Guidelines for sensory evaluation laboratories. STP 913. Pennsylvania: American Society for Testing and Materials.

Bais, H. P., \& Ravishankar, G. A. (2001). Cichorium intybus L. - Cultivation, processing, utility, value addition and biotechnology, with an emphasis on current status and future prospects. Journal of the Science of Food and Agriculture, 81, 467-484.

Banon, S., Costa, E., Gil, M. D., \& Garrido, M. D. (2003). A comparative study of boar taint in cooked and dry-cured meat. Meat Science, 63, 381-388.

Byrne, D. V., \& Hansen, L. L. (2005). The effect of feeding different concentration of dried chicory roots (Cichorium intybus L.) for 7, 14 or 21 days prior to slaughter on the quality characteristics of meat from entire male pigs. Part II. Sensory boar taint characterisation and chemical predictivity. Project Report: The Royal Veterinary and Agricultural University, Copenhagen, Denmark.

Byrne, D. V., Bak, L. S., Bredie, W. L. P., Bertelsen, G., \& Martens, M. (1999). Development of a sensory vocabulary for warmed-over flavour: Part I. In porcine meat. Journal of Sensory Studies, 14, 47-65.

Byrne, D. V., O'Sullivan, M. G., Dijksterhuis, G., Bredie, W. L. P., \& Martens, M. (2001) Sensory panel consistency during the development of a vocabulary for warmedover flavour. Food Quality and Preference, 12, 171-187.

Byrne, D. V., Thamsborg, S. M., \& Hansen, L. L. (2007). A sensory description of boar taint and the effects of crude and dried chicory roots (Cichorium intybus L.) and inulin feeding in male and female pork. Meat Science, 79, 252-269.

Canh, T. T., Verstegen, M. W., Aarnink, A. J., \& Schrama, J. W. (1997). Influence of dietary factors on nitrogen partitioning and composition of urine and faeces of fattening pigs. Journal of Animal Science, 75, 700-706.

Claudi-Magnussen, C., \& Hansen, L. L. (2005). 5310: Svinefodring næringsstofudnyttelse, produktkvalitet og sundhed (OrganicPigFeed) FØJOprojekt II-7. Work Package 3. Pig nutrition, product quality and health, Final report. In Danish. Report No. 01793, Danish Meat Research Institute. Organic Eprints 5310.

Claus, R., Lösel, D., Lacorn, M. Mentschel, J., \& Schenkel, H. (2003). Effects of butyrate on apoptosis in the pig colon and its consequences for skatole formation and tissue accumulation. Journal of Animal Science, 81, 239-248.

Claus, R., Weiler, U., \& Herzog, A. (1994). Physiological aspects of androstenone and skatole formation in the boars - A review with experimental data. Meat Science, 38, 289-305.

Danish Bacon and Meat Council (2002). Nutritional requirements. The National Committee for Pig Production.

Dijksterhuis, G. B., Engel, B., Walstra, P., Font i Furnols, M., Agerhem, H., Fischer, K., et al. (2000). An international study on the importance of androstenone and skatole for boar taint: II. Sensory evaluation by trained panels in seven European countries. Meat Science, 54, 261-269.

EFSA (European Food Safety Authority) (2004). Welfare aspects of castration of piglets; scientific report of the scientific panel for animal health and welfare ion on a request from the Commission related to welfare aspects of the castration of piglets, AHAW/04-087. Accepted by unanimity by the Panel at the Plenary Meeting held on 12-13th July 2004

Fernadez, J. A., \& Batterham, E. S. (1995). The nutritive value of lupin-seed and dehulled lupin seed meals as protein sources for growing pigs as evaluated by different techniques. Animal Feed Science and Technology, 53, 279-296.

Fernandez, J. A., \& Danielsen, V. (2006). Reduceret protein i foderet til økologiske slagtesvin fodret med forskellige mængderlupin. DJF-Report No. 73 [in Danish].

Gower, J. (1975). Generalized procrustes analysis. Psychometrica, 40, 31-55.

Hansen, L. L. (2005). The effect of feeding different concentration of dried chicory roots (Cichorium intybus L.) for 7, 14 or 21 days prior to slaughter on the quality characteristics of meat from entire male pigs. Part I: Animal production and boar taint chemical measurements. Report. Danish Institute of Agriculture Science, Research Centre Foulum, Tjele, Denmark.

Hansen, L. L., \& Claudi-Magnussen, C. (2004). Feeding with lupines reduces the amount of skatole in organic pigs. DARCOFenews, Newsletter from Danish Research Centre for Organic Farming (December 2004 No. 4.).

Hansen, L. L., Larsen, A. E., Jensen, B. B., Hansen-Møller, J., \& Bardon-Gade, P. (1994). nfluence of stocking rate and feaces deposition in the pen at different temperatures on skatole concentration (boar taint) in subcutaneous fat. Animal Production, 59, 99-110.

Hansen, L. L., Mejer, H., Thamsborg, S. M., Byrne, D. V., Roepstorff, A., Karlsson, A. H., et al. (2006). Influence of chicory roots (Chicorium intybus L.) on boar taint in entire male and female pigs. Animal Science, 82, 359-368.

Hansen-Møller, J. (1998). Analytical methods for determination of boar taint compounds. In W. Klinth Jensen (Ed.), Skatole and boar taint (pp. 21-40). Roskilde, Denmark: Danish Meat Research Institute.

Honikel, K. O. (1998). Reference methods for the assessment of physical characteristics of meat. Meat Science, 49, 447-457.

ISO (1988). International Standard 8589. Sensory analysis - General guidance for the design of test rooms. Ref. No. ISO 8589:1988 (E). Genève: International Organization for Standardization.

ISO (1993). International Standard 8586-1. Sensory analysis - General guidance for the selection, training and monitoring of assessors. Part 1: Selected assessors. Ref. No. ISO 8586-2 1994 (E). Genève: International Organization for Standardization.

ISO (1994a). International Standard 11035. Sensory analysis - Identification and selection of descriptors for establishing a sensory profile by a multidimensional approach. Ref. No. ISO 11035:1994 (E). Genève: International Organization for Standardization.

ISO (1994b) International Standard 8586-2. Sensory analysis - General guidance for the selection, training and monitoring of assessors. Part 2: Expert. Ref. No. ISO 858621994 (E). Genève: International Organization for Standardization.

Jensen, B. B., \& Jensen, M. T. (1998). Microbial production of skatole in the digestive tract of entire male pigs. In W. K. Jensen (Ed.), Skatole and boar taint (pp. 41-76). Roskilde, Denmark: Danish Meat Research Institute.

Jensen, M. T., Cox, R. P., \& Jensen, B. B. (1995). Microbial production of skatole in the hind gut of pigs given different diets and its relation to skatole deposition in backfat. Animal Science, 61, 293-304.

Jensen, M. T., \& Hansen, L. L. (2006). Feeding with chicory roots reduces the amount of odorous compounds in colon and rectal contents of pigs. Animal Science, 82, 369-376.

Larsson, K., \& Bengtsson, S. (1983). Determination of readily available carbohydrates in plant material. Chemistry methods Report No. 22. National Laboratory Agriculture Chemistry, Uppsala.

Lösel, D., Lacorn, M., Buttner, D., \& Claus, R. (2006). Flavour improvement in pork from barrows and gilts via inhibition of intestinal skatole formation with resistant potato starch. Journal of Agricultural and Food Chemistry, 54, 5990-5995.

Lundström, K., Malmfors, B., Stern, S., Rydhmer, L., Eliasson-Selling, L., Mortensen, A. B., et al. (1994). Skatole levels in pigs selected for high lean tissue growth rate on different dietary protein levels. Livestock Production Science, 38, 125132.

Madsen, A., Petersen, J. S., \& Soegaard, A. (1990). Anatomic content of the female and castrated male pig fed according to scale or ad libitum and slaughtered at 20, 50, 80 or $110 \mathrm{~kg}$. Communication No. 769. National Institute of Animal Science DIAS (Denmark) [in Danish].

Marlett, J. A., Hosig, K. B., Vollendorf, N. W., Shinnick, F. L., Haack, V. S., \& Story, J. A. (1994). Mechanism of serum cholesterol reduction by oat bran. Hepatology, 20, 1450-1457.

Martens, H., \& Martens, M. (2001). Interpretation of many types of data $X \Leftrightarrow Y$ : Exploring relationships in interdisciplinary data sets (chapter 8). In Multivariate analysis of quality. An Introduction (pp. 139-145). London, England: John Wiley \& Sons Ltd..

Martínez-Villaluenga, C., Frías, J., \& Vidal-Valverde, C. (2005). Raffinose family oligosaccharides and sucrose contents in 13 Spanish lupine cultivars. Food Chemistry, 91, 645-649.

Meilgaard, M., Civille, G. V., \& Carr, B. T. (2006). Measuring responses. In Sensory evaluation techniques (4th ed., pp. 45-62). Florida: CRC press.

Mortensen, A. B., \& Sørensen, S. E. (1984). Relationship between boar taint and skatole determined with a new analysis method. In Proc. 30th European meeting of meat research workers, Bristol (pp. 394-396).

Nahm, K. H. (2003). Influence of fermentable carbohydrates on shifting nitrogen excretion and reducing ammonia emission of pigs. Critical Reviews in Environmental Science and Technology, 30, 165-186.

Passonneau, J. V., \& Lowry, O. H. (1993). Enzymatic analysis - A practical guide. Totowa, New Jersey: The Humana Press.

Patterson, R. L. S. (1968). Androstenone: Compound responsible for taint in boar fat. Journal of the Science of Food and Agriculture, 19, 31-38.

Rideout, T. C., Fan, M. Z., Cant, J. P., Wagner-Riddle, C., \& Stonehouse, P. (2004). Excretion of major odor-causing and acidifying compounds in response to dietary supplementation of chicory inulin in growing pigs. Journal of Animal Science, 82, 1678-1684.

Zamaratskaia, G. (2004). Factors involved in boar taint; Influence of breed, age, diet and raising conditions. Doctoral Thesis, Swedish University of Agricultural Sciences, Uppsala.

Zamaratskaia, G., Babol, J., Andersson, H. K., Andersson, K., \& Lundström, K. (2005). Effect of live weight and dietary supplement of raw potato starch on the levels of skatole, androstenone, testosterone and oestrone sulphate in entire male pigs. Livestock Production Science, 93, 235-243. 